\title{
One-year outcomes of novel BioMime Morph tapered stent in long and multiple coronary artery lesions
}

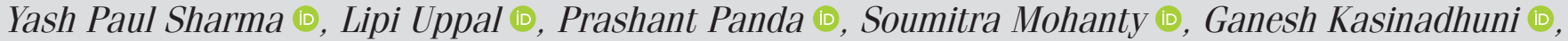 \\ Darshan Krishnappa (1D, Saurabh Mehrotra (iD, Ankur Gupta (D), Krishna Prasad (1), \\ Krishna Santosh (iD, Dinakar Bootla (iD, Soumitra Ghosh (i)
}

Department of Cardiology, Post Graduate Institution of Medical Education and Research (PGIMER); Chandigarh-India

\section{ABSTRACT}

Objective: Even with the immense progress achieved in the field of percutaneous coronary interventions (PCls), treatment of diffuse long atherosclerotic coronary artery disease continues to remain a challenge for durable outcomes. The downstream reduction in diameter along the lesion length of a coronary artery may compel the cardiologist to use either 2 overlapping stents of different diameters or a single long stent leading to stent-vessel mismatch at the edges. Recently, Meril Life Sciences Pvt. Ltd., India, has introduced a long-tapered sirolimus-eluting stent (SES) system, BioMime Morph, which conforms to the normal tapered geometry of coronary arteries along with adequate lesion coverage. In this study, we aimed to provide real world experience regarding the safety and efficacy of the BioMime Morph SES over a follow-up of one year.

Methods: This was a single center, retrospective study involving 172 participants who underwent PCI with the BioMime Morph SES. Mean length of the target lesion was $34.4 \pm 10.4 \mathrm{~mm}$, and mean stent length was $53.2 \pm 8.7 \mathrm{~mm}$. The most frequent revascularized vessel was the left anterior descending artery (LAD) in 97 lesions (54.4\%).

Results: Major adverse cardiac events (MACE) (defined as a composite of target vessel myocardial infarction, target lesion revascularization, and death due to a cardiac cause) at 1, 6, and 12 months were seen in $4(2.3 \%), 7(4.0 \%)$, and 8 (4.7\%) patients, respectively. Overall, 5 cardiac deaths and 2 definite stent thrombosis were observed in the study.

Conclusion: The study suggests that the novel BioMime Morph SES is an effective and a safe option for PCl in the treatment of long diffuse atherosclerotic lesions.

Keywords: diffuse disease, long lesions, multiple lesions, BioMime Morph, tapered stent, percutaneous coronary revascularization

Cite this article as: Sharma YP, Uppal L, Panda P, Mohanty S, Kasinadhuni G, Krishnappa D, et al. One-year outcomes of novel BioMime Morph tapered stent in long and multiple coronary artery lesions. Anatol J Cardiol 2021; 25: 896-901.

\section{Introduction}

Optimal stent sizing is paramount for ideal outcomes after a percutaneous coronary intervention (PCI). Although underexpanded stents increase both the risk of stent thrombosis and in-stent restenosis (ISR), overexpansion as high as 1.2:1 is asso- ciated with neo-intimal proliferation, edge dissection, and vascular injury (1). Distal stent overexpansion becomes more prominent, especially during treatment of long diffuse coronary lesions $(>25 \mathrm{~mm})$ where the use of a single uniform diameter stent may pose difficulty in deployment across the gradually tapering vessel (2).

Address for Correspondence: Prashant Panda, MD,

Department of Cardiology, Post Graduate Institution of Medical Education and Research (PGIMER); Chandigarh-India

E-mail: prashantpanda85@gmail.com

Accepted Date: 02.06.2021 Available Online Date: 16.11.2021

(C) Copyright 2021 by Turkish Society of Cardiology - Available online at www.anatoljcardiol.com DOI:10.5152/AnatolJCardiol.2021.05763 


\section{HIGHLIGHTS}

- Diffuse atherosclerotic lesions pose a therapeutic challenge to interventional cardiologists despite the recent technical advancements.

- Novel BioMime Morph sirolimus eluting stent is an effective and safe option for percutaneous coronary intervention in treating long diffuse lesions.

Progressive reduction in the coronary artery diameter (tapering) up to $14 \%$ and $21 \%$ has been seen in proximal and distal left anterior descending artery (LAD), and up to $9 \%$ in the dominant right coronary artery (RCA) (3). In Asian adults, the average decremental ratio has been estimated to be $7.7 \%, 9.7 \%$, and $5.1 \%$ in the LAD, left circumflex artery, and RCA, respectively (4). Apart from the natural taper, the diameter reduction of the vessel is compounded by other factors including formation of a large side branch or negative remodelling distal to the stenotic lesion. Use of overlapping stents with different diameters are often considered in such cases, although it increases the incidence of stent fracture, late stent thrombosis, side branch jailing, and ISR (5).

The novel BioMime Morph (Meril Life Sciences Pvt. Ltd., India) is a "Conformite Europeene" (CE) approved SES, which is a uniquely designed long tapered stent conforming to the natural tapering course of the coronaries. It is composed of a bioabsorbable polymer, poly-L glycolic acid and poly-L-lactic acid, built on ultrathin (65 micron) stent struts with cobalt chromium platform and hybrid design. The stent elutes sirolimus $(1.25 \mu \mathrm{g} /$ $\mathrm{mm}^{2}$ of the stent surface area) within 30-40 days after implantation. The stent inflation is guided by a tapered balloon on which the stent system is mounted and is estimated to achieve diameters (proximal to distal) of $2.75-2.25 \mathrm{~mm}, 3.0-2.5 \mathrm{~mm}, 3.5-2.75$ $\mathrm{mm}$, and $3.5-3.0 \mathrm{~mm}$ in lengths of $30 \mathrm{~mm}, 40 \mathrm{~mm}, 50 \mathrm{~mm}$, and 60 $\mathrm{mm}$. It is especially useful for long lesions where the use of tapered single coronary stent may provide better vessel adaptation and superior long-term outcomes apart from curtailing the financial cost. A few studies evaluating the efficacy of this novel concept have found encouraging results $(6,7)$, In this study, we aimed to study the peri-procedural safety, and one-year outcomes of patients undergoing treatment with the BioMime Morph SES in the high-risk Indian population.

\section{Methods}

Our study was an observational, retrospective study conducted in a tertiary care center in North India and included patients who underwent treatment with the BioMime Morph SES from May 2017 to August 2019. All the patients undergoing $\mathrm{PCI}$ with at least one lesion treated with BioMime Morph SES were included in the study. We analyzed the baseline patient data, device-related and procedure-related details, and immedi- ate hospital outcomes for all the patients. An experienced cardiologist who was blinded to the outcome of the patients reviewed all the diagnostic angiograms. Quantitative coronary analysis (OCA) in an un-foreshortened view was performed using an automated edge detection technique to estimate the lesion characteristics including proximal reference diameter, distal reference diameter, length of the lesion, and percentage of diameter stenosis. Readily apparent radio-opacities within the vascular wall were identified as calcification and classified as mild, moderate, or severe (8). The thrombus burden and tortuosity were estimated in angiograms using the existing classification systems $(9,10)$. The angiographic success was defined as TIMI III flow at the end of the procedure and $<20 \%$ of the stenosis in distal landing zone. Aspirin and clopidogrel loading doses was given to all the patients, and procedural anticoagulation was achieved with intravenous heparin. Use of intra-procedural and post-procedural GPIIb/IIla inhibitors was as per the preference of the operator. Dual antiplatelet therapy which included aspirin (75-150 mg) along with either clopidogrel $(75 \mathrm{mg})$, ticagrelor (90 mg twice daily), or prasugrel (10 mg daily) were continued for all the patients for one year. Follow-up data were collected regarding clinical status and occurrence of major adverse cardiac events (MACE), which was defined as the composite of target vessel myocardial infarction (MI), ischemia driven target lesion revascularization (TLR), and cardiac death. $\mathrm{MI}$ was defined as either development of new pathological 0 waves or the absence of 0 wave in in the electrocardiogram, creatine kinase elevation $>2$ times the upper limit of normal, along with new-onset ischemic symptoms. Any repeat intervention for the lesion at the target site or within $5 \mathrm{~mm}$ proximal or distal to the stent edge was defined as TLR. Any death with no definite non-cardiac cause was defined as cardiac death. Stent thrombosis was classified as definite, probable, or possible as well as early, late, or very late as per the Academic Research Consortium (11).

\section{Statistical analysis}

The categorical variables were described as frequencies (percentages), and continuous variables were presented as mean \pm standard deviation in this study. The independent predictors of long-term cardiovascular events from procedurerelated, device-related, or patient-related variables were assessed using Cox regression analysis, and a $p$ value of $<0.05$ was considered significant. The event-free survival curve was constructed using Kaplan-Meier method. Data analysis was done using Statistical Package for Social Sciences, version 23.0 (SPSS, IBM Corporation, Chicago, IL, USA).

\section{Results}

\section{Baseline demographic characteristics (Table 1)}

Mean (SD) age of the study population was $57.4 \pm 9.5$ years with men constituting $80.8 \%$ of the study group. Conventional 


\begin{tabular}{|c|c|c|}
\hline Characteristics & & $\mathrm{n}=172$ \\
\hline Age (Mean \pm SD) (years) & & $57.4 \pm 9.5$ \\
\hline Sex (Male) & & $139(80.8 \%)$ \\
\hline Type 2 diabetes & & $73(42.4 \%)$ \\
\hline Hypertension & & $61(35.5 \%)$ \\
\hline Smoking & & $54(31.4 \%)$ \\
\hline Previous PCl & & $25(14.5 \%)$ \\
\hline Previous CABG & & $0(0 \%)$ \\
\hline History of stroke & & $1(0.6 \%)$ \\
\hline CKD (GFR <30 mL/min) & & $11(6.4 \%)$ \\
\hline EF $($ Mean $\pm S D) \%$ & & $48.19 \pm 12.1$ \\
\hline Mean follow-up (months) & & $19.56 \pm 8.2$ \\
\hline \multirow[t]{6}{*}{ Presentation } & Anterior wall MI & $31(18.0 \%)$ \\
\hline & Inferior wall MI & $25(14.5 \%)$ \\
\hline & Posterior wall MI & $1(0.6 \%)$ \\
\hline & NSTEMI & $16(9.3 \%)$ \\
\hline & Unstable angina & $46(26.7 \%)$ \\
\hline & Chronic stable angina & $53(30.8 \%)$ \\
\hline \multirow{3}{*}{$\begin{array}{l}\text { Post-procedure } \\
\text { antiplatelets }\end{array}$} & Aspirin and clopidogrel & $115(66.9 \%)$ \\
\hline & Aspirin and ticagrelor & $54(31.4 \%)$ \\
\hline & Aspirin and prasugrel & $03(1.74 \%)$ \\
\hline \multicolumn{3}{|c|}{$\begin{array}{l}\text { CKD - chronic kidney disease; EF - ejection fraction; GFR - glomerular filtration rate; } \\
\text { MI - myocardial infarction; NSTEMI - non-ST elevation myocardial infarction; PCI - } \\
\text { percutaneous coronary intervention; SD - standard deviation }\end{array}$} \\
\hline
\end{tabular}

risk factors including hypertension (HTN), type 2 diabetes mellitus (DM), chronic kidney disease (CKD), and smoking were present in 61 (35.5\%), $73(42.4 \%), 11$ (6.3\%), and $54(31.4 \%)$ patients, respectively. Of all the patients, $108(62.8 \%)$ presented with a diagnosis of acute coronary syndrome, and $25(14.5 \%)$ had a history of prior $\mathrm{PCl}$.

\section{Baseline lesion characteristics (Table 2)}

A total of 178 lesions in 172 patients were treated with BioMime Morph SES (Meril Life Sciences Pvt. Ltd., India) with mean lesion length of $34.4 \pm 10.4 \mathrm{~mm}$. The lesions comprised 172 de novo and 6 lesions with ISR. The most commonly stented vessel was the LAD, which included $97(54.5 \%)$ of the deployed stents. Other characteristics including moderate to severe calcification, moderate to severe tortuosity, and large thrombus burden were seen in $11(6.2 \%), 4(2.2 \%)$, and $8(4.5 \%)$ patients, respectively. The most commonly deployed stent size was 3.5$3.0 \times 60 \mathrm{~mm}$ with $102(59.3 \%)$ patients undergoing single vessel stenting with the BioMime Morph SES, and 70 patients (40.6\%) undergoing multivessel $\mathrm{PCI}$ with BioMime Morph along with other stents. A total of 281 stents were deployed with a mean of 1.63 stents/patient.

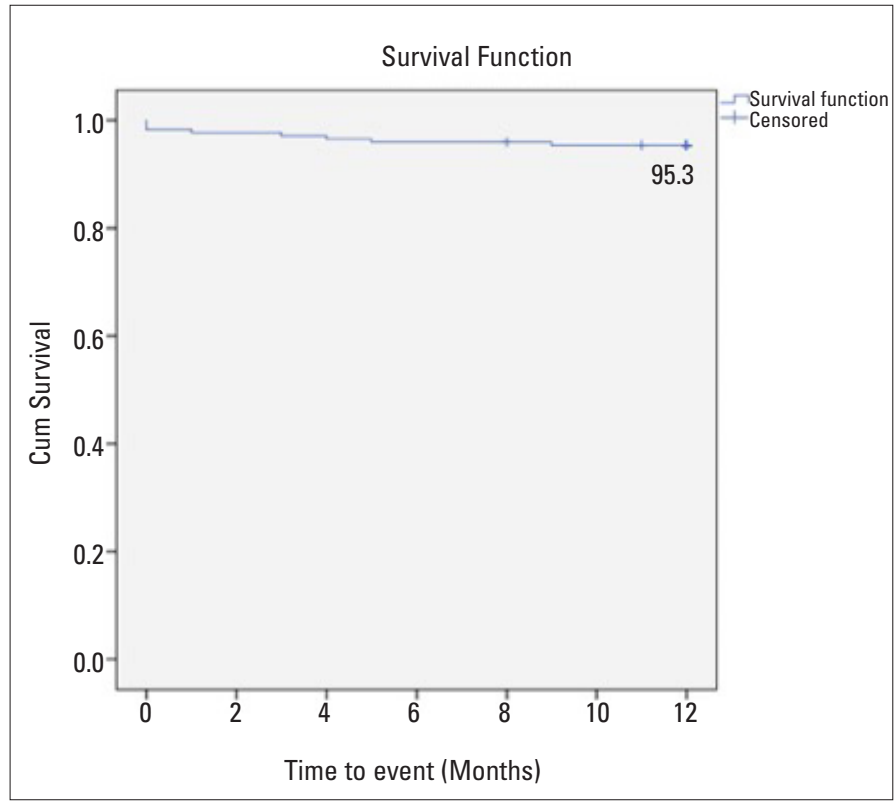

Figure 1. Time-to-event curve by Kaplan Meier at 12 months

\section{Procedural and clinical outcome (Table 3 )}

Two patients developed acute stent thrombosis during hospital stay, which was managed with thrombus aspiration and plain old balloon angioplasty. MACE was documented in $4(2.3 \%), 7(4.0 \%)$, and $8(4.7 \%)$ patients at the end of 1,6 , and 12 months of follow-up, respectively, comprising of 5 cardiac deaths, 2 definite stent thrombosis, and 1 target vessel myocardial infarction (Table 4). On performance of Cox regression analysis, none of the variables could significantly predict the risk of adverse events at 1 year including patient factors like DM, HTN, CKD, or procedural factors including stent length and number of stents. Kaplan-Meier curve for time to-event analysis is shown in Figure 1.

\section{Discussion}

This study observes the "real-world" experience of using a single long-tapered stent for the treatment of diffuse atherosclerotic disease and their outcomes over 1 year of follow-up in the high-risk Indian population.

Since the era of the bare-metal stent, long diffuse coronary artery lesion has remained an independent risk factor for ISR and adverse long-term outcomes (12). As residual plaque burden at the reference segment is one of the strongest predictors of edge restenosis, complete lesion coverage is often favored rather than spot stenting, although the use of overlapping stents increases the incidence of restenosis apart from increasing the procedure time and the financial costs $(5,13,14)$. With the advent of newer stent designs, superior longitudinal strength, and thinner struts, longer stents can often overcome the barrier imposed by vessel tortuosity calcification and achieve high success rates $(15,16)$. We attempted to treat such long diffuse lesions and CAD with novel, single, long tapering SES and assess their peri-procedural safety and outcomes. 


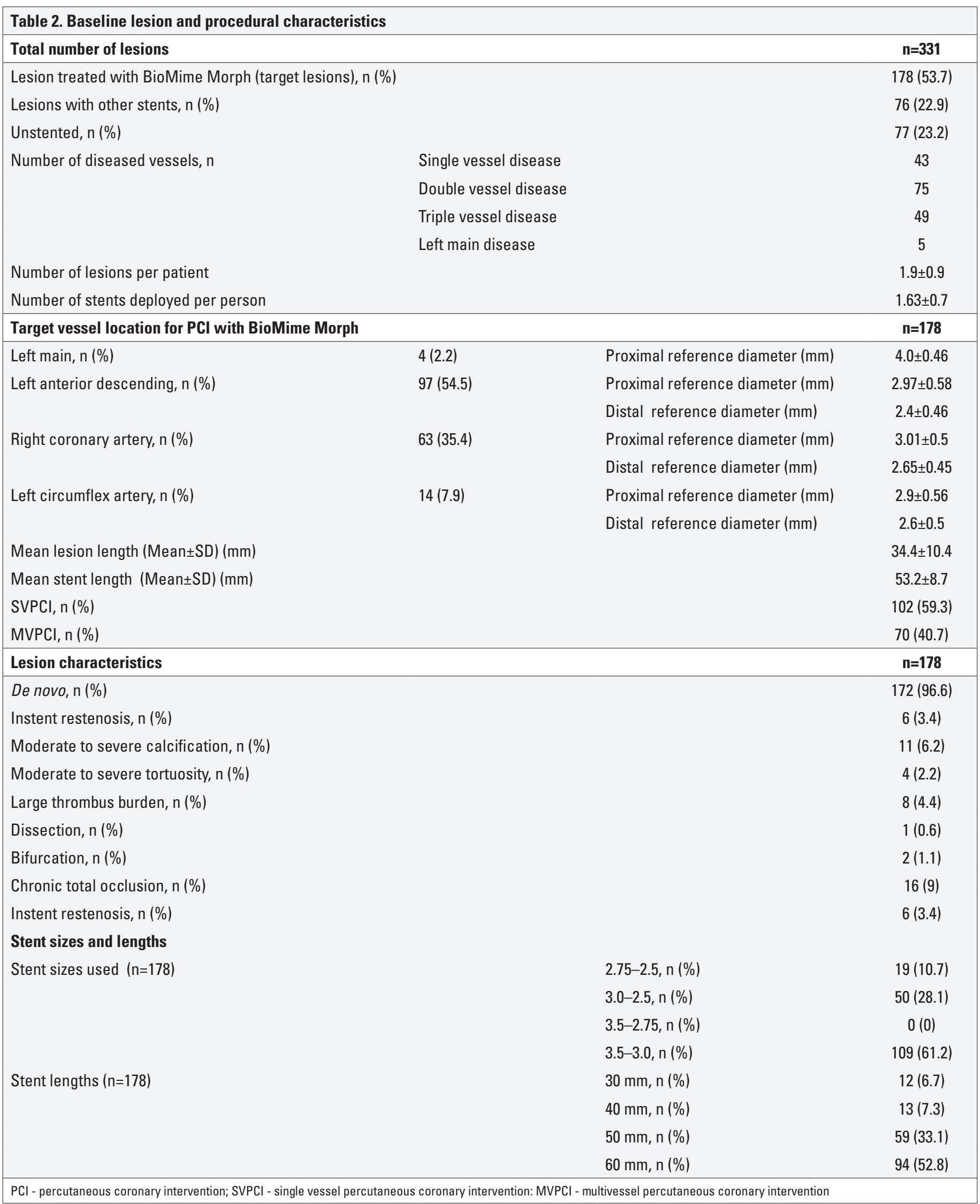




\begin{tabular}{|lc|}
\hline Table 3. Procedural outcomes \\
\hline Procedural outcomes & $\mathbf{n = 1 7 2}$ \\
\hline Successful procedure, $\mathrm{n}$ & $169(98.2 \%)$ \\
TIMI II flow, $\mathrm{n}$ & 2 \\
Edge dissection, $\mathrm{n}$ & 1 \\
Perforation, $\mathrm{n}$ & 1 \\
Side branch occlusion requiring stenting & 1 \\
\hline TIMI - thrombolysis in myocardial infarction & \\
\hline
\end{tabular}

Table 4. Major adverse cardiac events during hospital stay; 1, 6, and 12 months

\begin{tabular}{|c|c|c|c|c|c|}
\hline \multicolumn{2}{|l|}{ MACE } & $\begin{array}{c}n=172 \\
\text { hospital }\end{array}$ & $\begin{array}{c}1 \\
\text { month } \\
(\mathrm{n}=171)\end{array}$ & $\begin{array}{c}6 \\
\text { months } \\
(n=170)\end{array}$ & $\begin{array}{c}12 \\
\text { months } \\
\text { (n=167) }\end{array}$ \\
\hline \multicolumn{2}{|c|}{ All-cause death, $n$} & 1 & 2 & 5 & 7 \\
\hline \multicolumn{2}{|c|}{ Cardiac mortality, n } & 1 & 2 & 5 & 5 \\
\hline \multicolumn{2}{|c|}{ Non-cardiac mortality, $\mathrm{n}$} & 0 & 0 & 0 & 2 \\
\hline \multirow[t]{3}{*}{$\begin{array}{l}\text { Stent } \\
\text { thrombosis }\end{array}$} & $\begin{array}{l}\text { Definite stent } \\
\text { thrombosis }\end{array}$ & 2 & 2 & 2 & 2 \\
\hline & $\begin{array}{l}\text { Probable } \\
\text { stent } \\
\text { thrombosis }\end{array}$ & 1 & 2 & 2 & 2 \\
\hline & $\begin{array}{l}\text { Possible } \\
\text { stent } \\
\text { thrombosis }\end{array}$ & 0 & 0 & 1 & 1 \\
\hline \multicolumn{2}{|c|}{$\begin{array}{l}\text { Target lesion } \\
\text { revascularization, } \mathrm{n}\end{array}$} & 2 & 2 & 2 & 2 \\
\hline \multicolumn{2}{|c|}{ Target vessel MI, n } & 0 & 0 & 0 & 1 \\
\hline \multicolumn{2}{|l|}{ MACE, n } & $3(1.7 \%)$ & $4(2.3 \%)$ & $7(4.1 \%)$ & $8(4.7 \%)$ \\
\hline
\end{tabular}

Excellent post-procedure angiographic results were obtained with successful deployment, achieved in $98.2 \%$ of the cases with mean lesion length of $34.4 \pm 10.4 \mathrm{~mm}$. Five patients suffered from a cardiac death, 2 had target lesion revascularization, and 1 had target vessel revascularization over a follow-up of 1 year in the index study.

Recent studies investigating the use of single long stents (SLS) for treatment of diffuse coronary lesions have also shown fairly high success rates $(17,18)$. Mori et al. (18) evaluated the clinical outcomes and angiographic endpoints in patients undergoing SLS versus overlapped stents for diffuse coronary artery lesions and experienced $92.9 \%$ vs. $93.1 \%(p=0.91)$ freedom from MACE and $94.5 \%$ vs. $95.1 \%$ ( $p=0.79$ ) freedom from target lesion revascularization at the end of 1 year in the single stent vs. multiple overlapped stent groups, respectively. In a similar study of 643 patients with diffuse lesions undergoing treatment with either SLS $(>40 \mathrm{~mm})$ or overlapping stents, adverse cardiac events were observed in $6.2 \%$ of the patients at the median interval of 20 months in the single stent group (17). In both the studies, the authors could not find any significant difference among MACE associated with use of single stents vs overlapped stents, although the use of contrast volume, duration of procedure, and radiation dose was increased with the use of overlapping stents (17). New tapered BioMime Morph SES has previously been evaluated in a multicenter study of 362 patients for de novo lesions with decremental diameters and was associated with low peri-procedural and post-procedural complications (2\% MACE at 12 months, single incidence of acute stent thrombosis) (6). Our study had comparable number of patients with comorbidities; type 2 DM in $42.4 \%$, HTN in $35.5 \%$, and CKD in $6.4 \%$ of the study cohort. Slightly increased rate of MACE in our study, however, may be attributed to the high number of patients with complex disease and undergoing MV PCI ( $n=70,41 \%)$ signifying high atherosclerotic disease burden. Previous small studies with BioMime Morph SES in diffuse lesions $(>48 \mathrm{~mm})$ and chronic total occlusions (СTO) also have demonstrated good vessel apposition without any significant complications $(19,20)$. We previously reported successful use of the same in a patient with diseased left main and RCA CTO undergoing multivessel $\mathrm{PCl}$ with satisfactory results (21).

We tried to assess the influence of various patient-related or stent-related factors on incidence of MACE in our study but could not find any significant predictors. The limited number of patients with only one year of follow up may have been contributory. In addition, the increased number of stents and stent length have been correlated with binary stenosis and late lumen loss in many studies (22); however, as we did not perform followup angiography in patients, we could not appreciate the same.

\section{Study limitations}

A lack of a control arm and its retrospective nature were inherent limitations of this study. The choice of stents used in other lesions, procedural strategy, and post-procedure choice of antiplatelet drugs were at the discretion of the operator, all of which can influence outcomes.

In patients with long diffuse lesions, we are occasionally faced with a dilemma regarding the feasibility of the use of long single stents. Although single stents may be faced with their own difficulties in the form of deliverability in a calcified and tortuous vessel, our study reinstates their successful use with acceptable mid-term outcomes. According to our study, newer BioMime Morph SES with its unique design is a safe option to consider in long and diffusely diseased coronary vessel with dimuniting diameters.

\section{Conclusion}

Our study demonstrates reassuring evidence of feasibility and safety of the long tapering BioMime Morph SES in a realworld scenario and even in complex coronary lesions. However, randomized controlled trials are required to assess the economic benefits and long-term outcomes of these stents in diverse clinical settings. 
Ethics approval and consent to participate: Owing to the retrospective nature of this study no ethical approval or consent was sought.

Conflict of interest: None declared.

Peer-review: Externally peer-reviewed.

Author contributions: Concept - Y.P.S., P.P., S.Mehrotra, A.G.; Design - Y.P.S., P.P., S.Mehrotra, A.G.; Supervision - Y.P.S., P.P., S.Mehrotra, A.G.; Fundings - None; Materials - Y.P.S., P.P., S.Mehrotra, A.G.; Data collection \&/or processing - L.U., S.Mohanty, G.K., D.K., K.P., K.S., D.B., S.G.; Analysis \&/or interpretation - L.U., S.Mohanty, G.K., D.K., K.P., K.S., D.B., S.G.; Literature search - L.U., S.Mohanty, G.K., D.K., K.P., K.S., D.B., S.G.; Writing - L.U., S.Mohanty, G.K., D.K., K.P., K.S., D.B., S.G.; Critical review - Y.P.S., L.U., P.P., S.Mohanty, G.K., D.K., S.Mehrotra, A.G., K.P., K.S., D.B., S.G.

\section{References}

1. Russo RJ, Silva PD, Yeager M. Coronary artery overexpansion increases neointimal hyperplasia after stent placement in a porcine model. Heart 2007; 93: 1609-15. [Crossref]

2. Phan TQ, Nguyen LH, Nguyen LV, Lee WS, Won H, Cho I, et al. Imaging Characteristics of Mismatch Lesions: An Angiographic and Intravascular Ultrasound Analysis of 1369 Coronary Lesions. Angiology 2019; 70: 756-64. [Crossref]

3. Zubaid M, Buller C, Mancini GB. Normal angiographic tapering of the coronary arteries. Can J Cardiol 2002; 18: 973-80.

4. Zhang LR, Xu DS, Liu XC, Wu XS, Ying YN, Dong Z, et al. Coronary artery lumen diameter and bifurcation angle derived from CT coronary angiographic image in healthy people. Zhonghua Xin Xue Guan Bing Za Zhi 2011; 39: 1117-23. [Article in Chinese]

5. Rikhtegar F, Edelman ER, Olgac U, Poulikakos D, Kurtcuoglu V. Drug deposition in coronary arteries with overlapping drug-eluting stents. J Control Release 2016; 238: 1-9. [Crossref]

6. Patted SV, Jain RK, Jiwani PA, Suryavanshi S, Raghu TR, Raveesh $\mathrm{H}$, et al. Clinical Outcomes of Novel Long-Tapered SirolimusEluting Coronary Stent System in Real-World Patients With Long Diffused De Novo Coronary Lesions. Cardiol Res 2018; 9: 350-7. [Crossref]

7. Lupi A, Ugo F, De Martino L, Infantino V, Iannaccone M, lorio S, et al. Real-World Experience With a Tapered Biodegradable PolymerCoated Sirolimus-Eluting Stent in Patients With Long Coronary Artery Stenoses. Cardiol Res 2020; 11: 219-25. [Crossref]

8. Mintz GS, Popma JJ, Pichard AD, Kent KM, Satler LF, Chuang YC, et al. Patterns of calcification in coronary artery disease. A statistical analysis of intravascular ultrasound and coronary angiography in 1155 lesions. Circulation 1995; 91: 1959-65. [Crossref]

9. Sianos G, Papafaklis MI, Serruys PW. Angiographic thrombus burden classification in patients with ST-segment elevation myocardial infarction treated with percutaneous coronary intervention. $J$ Invasive Cardiol 2010; 22 (10 Suppl B): 6B-14B.
10. Eleid MF, Guddeti RR, Tweet MS, Lerman A, Singh M, Best PJ, et al. Coronary artery tortuosity in spontaneous coronary artery dissection: angiographic characteristics and clinical implications. Circ Cardiovasc Interv 2014; 7: 656-62. [Crossref]

11. Mauri L, Hsieh WH, Massaro JM, Ho KK, D'Agostino R, Cutlip DE. Stent thrombosis in randomized clinical trials of drug-eluting stents. N Engl J Med 2007; 356: 1020-9. [Crossref]

12. Applegate RJ, Sacrinty MT, Kutcher MA, Santos RM, Gandhi SK, Little WC. Effect of length and diameter of drug-eluting stents versus bare-metal stents on late outcomes. Circ Cardiovasc Interv 2009; 2: 35-42. [Crossref]

13. Kang SJ, Cho YR, Park GM, Ahn JM, Kim WJ, Lee JY, et al. Intravascular ultrasound predictors for edge restenosis after newer generation drug-eluting stent implantation. Am J Cardiol 2013; 111: 1408-14. [Crossref]

14. Amirzadegan $A$, Hasanabadi $M$, Saadatagah $S$, Afarideh $M$, Omidi $\mathrm{N}$, Aghajani $\mathrm{H}$, et al. Single Long Stents versus Overlapping Multiple Stents in the Management of Very Long Coronary Lesions: Comparisons of Procedures and Clinical Outcomes. J Tehran Heart Cent 2019; 14: 94-102. [Crossref]

15. Patra S, Kumar D, Pande A, Mukherjee SS, Roy RR, Halder A, et al. Procedural safety and outcome of ultrathin strut stents $(<60 \mu \mathrm{m})$ in the management of very long coronary artery stenosis $(>30 \mathrm{~mm})$ - A retrospective real world study. Am J Cardiovasc Dis 2020; 10: 182-8.

16. Yue X, Guo J, Zhang J, Cao C, Zhang Z, Shen D, et al. Evaluation of Mechanical Performances of Stents with $38 \mathrm{~mm}$ Length in Long Lesion. Biomed Res Int 2020; 2020: 2594161. [Crossref]

17. Jurado-Román A, Abellán-Huerta J, Requena JA, Sánchez-Pérez I, López-Lluva MT, Maseda-Uriza R, et al. Comparison of Clinical Outcomes Between Very Long Stents and Overlapping Stents for the Treatment of Diffuse Coronary Disease in Real Clinical Practice. Cardiovasc Revasc Med 2019; 20: 681-6. [Crossref]

18. Mori N, Okamoto N, Tanaka A, Yano M, Makino N, Egami $\mathrm{Y}$, et al. Comparison of Angiographic and 1-Year Outcomes Between a Long Single Stent and Overlapping Double Stents in Patients With Newer-Generation Drug-Eluting Stents for Long Narrowings. Am J Cardiol 2016; 117: 1724-8. [Crossref]

19. Valero E, Consuegra-Sánchez L, Miñana G, García-Blas S, Rodríguez JC, Moyano $\mathrm{P}$, et al. Initial experience with the novel BioMime $60 \mathrm{~mm}$-long sirolimus-eluting tapered stent system in long coronary lesions. Eurolntervention 2018; 13: 1591-4. [Crossref]

20. Zivelonghi C, van Kuijk JP, Nijenhuis V, Poletti E, Suttorp MJ, van der Heyden JAS, et al. First report of the use of long-tapered sirolimuseluting coronary stent for the treatment of chronic total oc clusions with the hybrid algorithm. Catheter Cardiovasc Interv 2018; 92: E299-307. [Crossref]

21. Sharma YP, Santosh K, Panda P, Prasad K, Uppal L, Y S S, et al. Use of BioMime Morph stent in treating left main triple vessel disease: a case report. Egypt Heart J 2020; 72: 47. [Crossref]

22. Kastrati A, Elezi S, Dirschinger J, Hadamitzky M, Neumann FJ Schömig A. Influence of lesion length on restenosis after coronary stent placement. Am J Cardiol 1999; 83: 1617-22. [Crossref] 